\title{
PHARMACOGNOSTICAL AND PHYSICOCHEMICAL ANALYSIS OF TODDALIA ASIATICA (L.) LAM.
} RUTACEAE

\author{
S. BANGAJAVALLI* \\ Department of Botany, Sri Parasakthi College for Women, Courtallam 627802 \\ Email: priya.kalavasan@gmail.com
}

Received: 15 Oct 2018, Revised and Accepted: 10 Dec 2018

\begin{abstract}
Objective: To characterize macroscopical and microscopical features of the leaf and stem of Toddalia asiatica (L.) Lam. RUTACEAE. Explore and establish the micro-morphology and quality control methods for this plant.

Methods: leaves and stem of Toddalia asiatica (L.) Lam. were collected for Pharmacognostic studies involving macros, microscopic evaluation and physicochemical parameters analysis like Ash value, Moisture content, Fluorescence analysis and phytochemicals.

Results: The leaf even and smooth on the adaxial side and highly undulate and densely hairy on the abaxial side. The midrib is very thick projecting much below the lower side of the leaf. The midrib is slightly revised above the adaxial side. It is thick and semicircular on the abaxial side. It is 950 $\mu \mathrm{m}$ thick and $900 \mu \mathrm{m}$ wide. The lateral vein hangs from the abaxial surface of the lamina. It is thick and prominent. There is no distinct differentiation of palisade and spongy mesophyll tissue. The lamina is $100 \mu \mathrm{m}$ thick. In the region of lateral veins, it is $160 \mu \mathrm{m}$ thick. Calcium oxalate crystals are fairly abundant in the secondary xylem parenchyma cells of the stem. Prismatic crystals also sparsly seen in the parenchyma cells outside the gelatinous fibre. The powder was also treated with different chemical reagents and changes in colour were studied in ordinary light and UV light. These fluorescence characters were determined according to the methods of Chase and Pratt. The total moisture content of the Toddalia asiatica was $46 \%$. The total ash content of the whole plant was found $96 \%$, the acid insoluble ash content of the whole plant was found $5 \%$, the watersoluble ash content of the whole plant was found $2 \%$, and the sulphated ash content of the whole plant was found $85 \%$. The extractive values obtained from different solvents were found in the Toddalia asiatica among all the extracts chloroform showed the highest percentage (81\%) followed by Ethanol $(45 \%)$ and Benzene (44\%). The distribution of different phytochemical constitutes in ethanol, benzene, chloroform acetone, petroleum ether and water of whole plant powder was evaluated qualitatively. The phytochemical such as carbohydrates, saponins, flavonoid, alkaloids, cardiac glycosides, phenols, coumarins, and steroids have been confirmed in the all the above extracts of the selected plant. Moreover, phytochemicals such as alkaloids, flavonoid, cardiac glycosides, courmarins, and steroids are also present in the sample and absence of, anthraquinone, steroid, terpenoid and fixed oil.
\end{abstract}

Conclusion: The observations confirmed that Toddalia asiatica obvious Pharmacognostic characteristics, which will be useful towards providing a reliable basis for identification, purity, quality, and classification of the plant. Results shall pave a way in the standardization of the drug.

Keywords: Pharmacognosy, Toddalia asiatica (L.)Lam, Physicochemical, microscopic, Florescence analysis

(C) 2019 The Authors. Published by Innovare Academic Sciences Pvt Ltd. This is an open-access article under the CC BY license (http://creativecommons.org/licenses/by/4.0/) DOI: http://dx.doi.org/10.22159/ijcpr.2019v11i1.31993

\section{INTRODUCTION}

Toddalia asiatica (L.) Lam. Is known as 'Milagarani' in Siddha system of medicine it is knowm as Kanchana in Ayurveda. Toddalia asiatica a very variable rambling, prickely, sarmentose shrub, distributed almost throughout India, ascending to an altitude of $2,500 \mathrm{~m}$. In south India, the plants are very common in the Nilgiri and palani hills and also in the scrubby jungles of Orissa. In the plains, particularly in dry situations, the plant assumes the form of a low shrub with smaller and narrower leaflets. Plant contains coumarins toddaalone, toddanol norbraylin, and 5,7,8-trimethoxy coumarin. Root contains benzophenanthridine alkaloid, hexacosanoic acid, Bsitosterol, arnottianamide. Root bark contains coumarins toddalenol, toddalosin, 5-methoxysuberenon, toddalenone, 8-formylli-alkaloidsbenzo(c) phenanthridine, alkaloids (des-N-Methylchelerythrine, oxychelerythrine, arnottianamide, oxyauicine, avicine, chelerythrine and chelerythrine psicyanide), quinoline alkaloids- $\mathrm{N}-\mathrm{methyl}$ flindersine, 4-methoxy-1, methyl-2, quinolone, skimmianine, integriquinone, triterpenoid B-amyrin, toddalinine, pimpinellin, isopimpinellen, chelerythrine and dihydro chelerythrine. leaves yield essential oil [1]. Root-bark is used to cure diaphoretic stomachic and antipyretic. It considered being a potent antimalarial drug showing both antiperiodic, antipyretic effects similar to those of cinchona alkaloids. Leaves chewed for stomach disorders. Local tribes used this plant for multiple applications like stomach problems, fever, cough and cold. It is also used in the treatment of various ailments a cough, Influenza, indigestion, rheumatic arthritis, sprains, bronchitis, nausea, diarrhea, and chest pain [2]. Toddalia asiatica is used traditionally in Kenya by many communities for the treatment of malaria, toothaches, as well as nasal and bronchial pains, and although all parts of the plant are claimed to have medicinal value [3].

\section{MATERIALS AND METHODS}

\section{Plant collection and authentication}

The aerial parts of the plant were collected from the Citraruvi, located in Courtallam hill, Western Ghats, Tamil Nadu. The plant was identified by Prof. P. Jayaraman, Plant Anatomy Research Centre, West Thambaram, Chennai, Tamil Nadu, and the voucher specimen were preserved in Department of Botany, Sri Parasakthi College for Women Courtallam (Autonomous) Herbarium, Tamilnadu, India. The stem and leaves were collected, shade dried, powdered in mechanical pulverized and stored in airtight containers for future use.

\section{Macroscopic and microscopic studies}

Macroscopic studies were carried out by simple determination, a technique like the shape, size, colour, odour, margin, and apex. The stem and leaf specimens were fixed in FAA and microtome slides were prepared and stained with toluidine blue [4-6]. Descriptive terms of the anatomical features are as given in the standard books [7]. Photomicrographs of with different magnifications were taken with Nikon Labphot 2 microscopic unit.

\section{Determination of physicochemical parameters}

Physicochemical characters such as ash value, extractive values and loss of weight on drying were determined as per Indian pharmacopeia [8-10]. 


\section{Fluorescence analysis}

The fine powders of the samples were examined under visible light and UV light $(254 \mathrm{~nm}$ and $365 \mathrm{~mm}$ ). These powders were also treated with acid, alkali and alcohol and changes in colour were recorded under visible and uv-light $[11,12]$.

\section{RESULT AND DISCUSSION}

Identification and evaluation of plant drugs by pharmacognostical studies is still more reliable, accurate and inexpensive. Standardization plays an important role in the production of phytopharmaceuticals of standard quality and purity.

\section{Anatomy of the leaf}

The leaf even and smooth on the adaxial side and highly undulate and densely hairy on the abaxial side. The midrib is very thick projecting much below the lower side of the leaf (fig. 1.1-1.3). The midrib is slightly revised above the adaxial side. It is thick and semicircular on the abaxial side. It is $950 \mu \mathrm{m}$ thick and $900 \mu \mathrm{m}$ wide. The epidermal layer of the midrib consists of small thick-walled and darkly stained cells with echinate tangential outer walls. The ground tissue includes circular compact parenchyma cells. Four or five layers of cells inner to the epidermis are small thick-walled collenchyma cells. Both adaxial and abaxial strand are collateral. The xylem elements occur in short more or less compact vertical lines. The xylem elements are angular and thick walled. The lumen of the cell is wide (fig. 2.). Pholem occurs in the form of an arc beneath the abaxial median vascular bundle is located along the outer border of the xylem segment. The xylem strands of adaxial and abaxial bundles are just aposed (fig. 2).

\section{Lateral vein}

The lateral vein hangs from the abaxial surface of the lamina. It is thick and prominent. It is basically similar to main midrib bundles. It has adaxial and abaxial vascular bundles which collateral and the xylem elements of the two bundles are aposed (fig. 1.2).

\section{Crystal distribution in the midrib}

Calcium oxalate crystals of druses are sparsely distributed in the pholem parenchyma and ground parenchyma cells (fig. 3.1). The druses are variable in size. The druses occur in a single in the parenchyma cells. In the pholem parenchyma cells, the druses are smaller in size than those located in the ground parenchyma.

\section{Structure of the lamina}

The adaxial surface of the lamina is smooth and even. The abaxial surface is prominently uneven with thick ridges and furrows. The ridges are due to thick prominently projecting lateral veins. The furrows are formed by the presence of large glandular trichomes. The glands have a short thin stock and funnel-shaped wide secretary body. The body of the gland is multicellular with darkly stained cells. The glandular trichomes are $50 \mu \mathrm{m}$ in size and $40 \mu \mathrm{m}$ wide. Apart from the glandular trichomes there are the dense cluster of stellate trichomes of non-glandular type are seen (fig. 3.2). The mesophyll tissue includes 4 or 5 layers of vertically elongated compact rectangular cells. There is no distinct differentiation of palisade and spongy mesophyll tissue. The lamina is $100 \mu \mathrm{m}$ thick. In the region of lateral veins it is $160 \mu \mathrm{m}$ thick.

\section{Stem}

The stem is circular in cross-sectional view measuring $3.4 \mu \mathrm{m}$ in diameter. The stem consists of the intact epidermal layer, thin, cortex, cortical gelatinous fibres, and dense hollow vascular cylinder. There is a central pith where the cells are disintegrated (fig. 4.1).

The epidermal cells of the stem are vertically elongated with darkly stained cell inclusions. The cortical one includes about six layers of polygonal thin walled compact parenchyma cells. In the inner boundary of the cortex occurs a thin continuous layer of gelatinous fibres (fig. 4.2 and 5.1). The fibres have inner mucilaginous cells walls. The inner cell wall stains dark purple in colour with toluidine blue stain (fig. 5.1). The secondary phloem is well developed and wide. It includes sieve elements and parenchyma cells in compact radial lines. The phloem rays are slightly wider and straight. The sieve elements are rectangular in shape and the companion cells are located on the lateral art of the sieve elements (fig. 5.1). The secondary xylem includes short radial multiples of vessels or solitary vessels. They are mostly elliptical in shape. Some of the vessels are circular and cell the vessel elements are thin walled. The fibres are thickly walled and lignified. The xylem rays are fairly prominent and straight. They include radially oblong thin-walled cells.

Calcium oxalate crystals are fairly abundant in the secondary xylem parenchyma cells. They are druses type (fig. 5.3). Prismatic crystals also sparsly seen in the parenchyma cells outside the gelatinous fibre.

\section{Toddalia asiatica (L.) Lam}

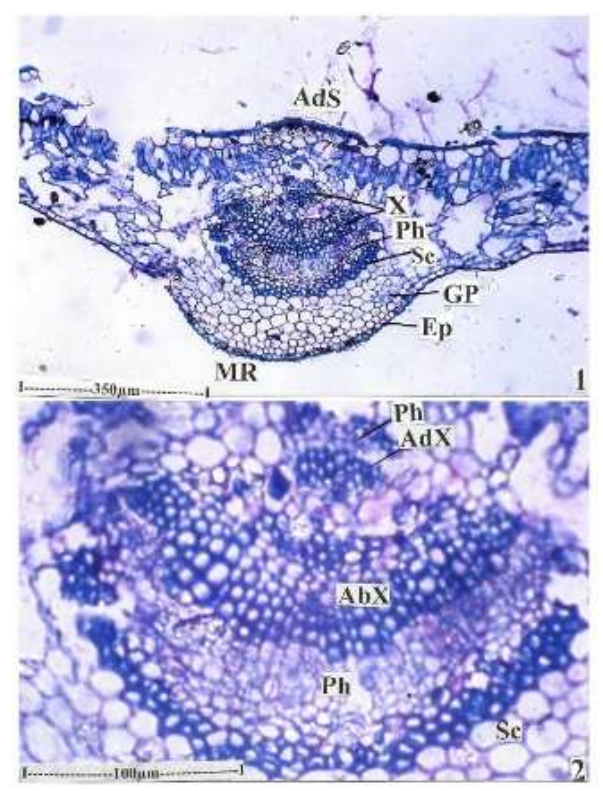

Fig. 1.1. T. S. of leaf through midrib, fig. 1.2. T. S. of midribEnlarged, (Abx-Abaxial xylem; Ads-Adaxial side; Adx-adaxial ylem; Ep-epidermis; G-Ground parenchyma; Ph-Phloem; MRMidrib; SC-Sclerenchyma; X-Xylem)

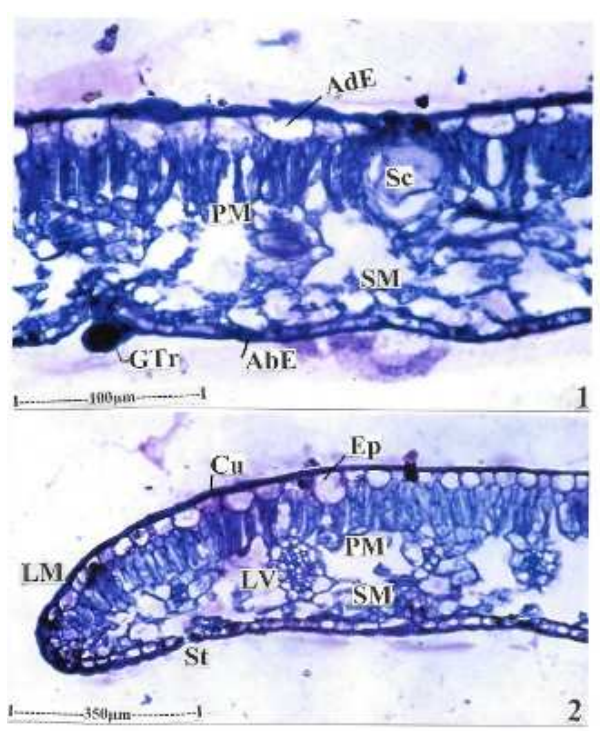

Fig. 2.1. _ T. S. of a lamina, fig. 2.2. T. S. of a leaf through leaf margin, (AdE-Adaxial Eidermis; AbE-Abaxial Epidermis; CUcuticle; EP-Epidermis; GTr-Ground trichome; LM-Leaf lamina; LV-Lateral vein; M-Palisade mesophyll; SC-Secretary cavity; SMSpongy mesophyll; St-Stomata) 


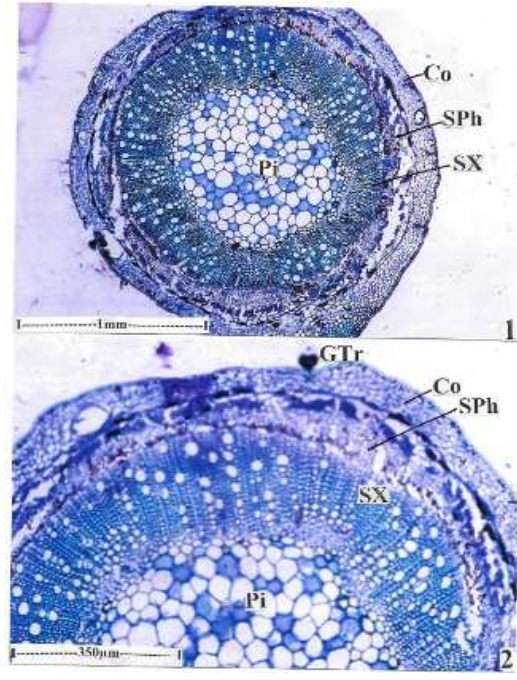

Fig. 3.1.-T. S. of stem-Entire view, fig. 3.2.-T. S. of stem-A sector enlarged, (Co-Cortex; Pi-Pith; GTr-Glandular trichome; Sphsecondary phloem; Sx-Secondary xylem)

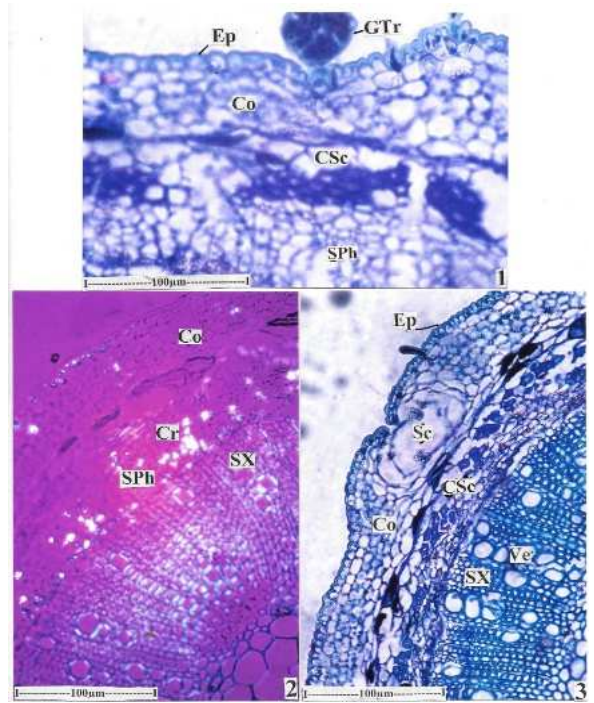

Fig. 4.1. T. S. of stem showing cortical zone and secondary phloem, fig. 4.2. Crystal distributed in the secondary phloem, fig. 4.3. T. S. of stem-A sector showing cortical secretary cavity, secondary phloem and secondary xylem, (Co-Cortex; Cr-Crystal; Ep-Epidermis; CSc-Cortical sclerenchyma; GTr-Glandular trichome; Sph-Secondary phloem; Sx-Secondary xylem; ScSecretary cavity; Ve-vessel)

\section{Physicochemical determination}

The percentage of loss of weight on drying, total ash, acid insoluble ash, water soluble ash, and sulphated ash were obtained by employing standard methods of analysis. The total moisture content of the Toddalia asiatica was $46 \%$. The total ash content of the whole plant was found $96 \%$, the acid insoluble ash content of the whole plant was found $5 \%$, the water-soluble ash content of the whole plant was found $2 \%$, and the sulphated ash content of whole plant was found $85 \%$, and the results are presented in the (table 1). The extractive values obtained from different solvents were found in the Toddalia asiatica among all the extracts chloroform showed the highest percentage (81\%) followed by Ethanol (45\%) and Benzene (44\%).(table 1).

\section{Fluroesence analysis}

The fluorescence analysis of the aerial part powder of Toddalia asiatica and their extracts in various solvents were examined under ordinary and Ultra Violet light $(365 \mathrm{~nm})$. The powder was also treated with different chemical reagents and changes in colour were studied in ordinary light and UV light. These fluorescence characters were determined according to the methods of Chase and Pratt [11]. The results are presented in table 2 .

\section{Preliminary phytochemical screening}

The distribution of different phytochemical constitutes in ethanol, benzene, chloroform acetone, petroleum ether and water of aerial part powder was evaluated qualitatively and the resulted are presented in table 3. The phytochemical such as carbohydrates, saponins, flavonoid, alkaloids, cardiac glycosides, phenols, coumarins and steroids have been confirmed in the all the above extracts of the selected plant. Moreover, phytochemicals such as alkaloids, flavonoid, cardiac glycosides, courmarins, and steroids are also present in the sample and absence of, anthroquinone, steroid, terpenoid and fixed oil. These secondary metabolites contribute significantly towards the biological activities of medicinal plants such as hypoglycemic, antidiabetic, antioxidant, antimicrobial, antiinflammatory, anticarcinogenic, antimalarial, anticholinergic, antileprosy activities etc. [13]. All the six selected medicinal plants for screening were found to possess tannins. Tannins have amazing stringent properties. They are known to hasten the healing of wounds and inflamed mucous membranes.

Flavonoids are also present in all six selected medicinal plants as a potent water-soluble antioxidant and free radical scavenger, which prevent oxidative cell damage and also have strong anticancer activity $[14,15]$. It also helps in managing diabetes-induced oxidative stress. Terpenoids have been found to be useful in the prevention and therapy of several diseases, including cancer. Terpenoids are also known to possess antimicrobial, antifungal, antiparasitic, antiviral, anti-allergenic, antispasmodic, antihyperglycemic, anti-inflammatory and immunomodulatory properties $[16,17]$. In addition, terpenoids can be used as protective substances in storing agriculture products as they are known to have insecticidal properties as well [18].

Table 1: Physicochemical characters of aerial part powder of Toddalia asiatica

\begin{tabular}{lll}
\hline S. No. & Description & Percentage (\%) \\
\hline 1 & Loss of weight on drying & 46 \\
2 & Total ash & 96 \\
3 & Acid-insoluble ash & 5 \\
4 & Water soluble ash & 2 \\
5 & Sulphated ash & 85 \\
6 & Petroleum ether & 26 \\
7 & Chloroform & 81 \\
8 & Acetone & 35 \\
9 & Ethanol & 45 \\
11 & Water & 35 \\
\hline
\end{tabular}


Table 2: Fluorescence analysis of aerial part powder of Toddalia asiatica

\begin{tabular}{|c|c|c|c|c|}
\hline S. No. & Sample & DayLight & UV(254 nm) & UV(365 nm) \\
\hline 1 & Powder & Light green & Pale green & Green \\
\hline 2 & $\mathrm{NaOH}$ & Green & Fluorescent Green & Light green \\
\hline 3 & $1 \mathrm{~N}$ Aqueous $\mathrm{NaOH}$ & Green & Light green & Dark green \\
\hline 4 & $1 \mathrm{~N}$ Alcoholic $\mathrm{NaOH}$ & Light green & Dark Green & Fluorescent green \\
\hline 5 & $50 \%$ sulphuric acid & Light green & Green & Dark green \\
\hline 6 & Picric acid & Pale green & Dark green & Green \\
\hline 7 & Ferric chloride & Pale brown & Brown & Dark brown \\
\hline 8 & Ammonia & Light Pale green & Pale green & Green \\
\hline 9 & Nitric acid & Light brick red & Brick red & Brick red \\
\hline 10 & Acetic acid & Green & Fluorescent green & Dark green \\
\hline 11 & $1 \mathrm{~N} \mathrm{Hcl}$ & Green & Pale green & Fluorescent green \\
\hline
\end{tabular}

Table 3: Preliminary phytochemical analysis of aerial part powder of Toddalia asiatica

\begin{tabular}{|c|c|c|c|c|c|c|}
\hline Constituents & Ethanol & Benzene & Chloroform & Acetone & PET & Water \\
\hline Alkaloids & + & - & + & + & - & + \\
\hline Anthraquinone & + & - & - & - & - & - \\
\hline Catechin & - & + & + & - & + & + \\
\hline Coumarin & - & - & - & - & + & + \\
\hline Flavonoid & - & + & + & - & + & + \\
\hline Phenol & - & + & + & + & + & + \\
\hline Quinine & + & - & - & - & - & - \\
\hline Saponin & - & - & - & - & - & - \\
\hline Steroids & + & + & + & - & - & - \\
\hline Tannin & + & + & - & + & - & + \\
\hline Terpenoid & + & - & - & - & - & - \\
\hline Reducing sugar & + & + & + & - & - & - \\
\hline Glycoside & - & + & + & - & - & - \\
\hline Xanthoprotein & + & - & - & + & - & + \\
\hline Fixed oil & + & + & - & + & + & + \\
\hline
\end{tabular}

\section{CONCLUSION}

After the present investigation, it can be concluded that the Pharmacognostical studies of the leaves and stem from Toddalia asiatica yielded a set of qualitative and quantitative parameters or standards that can serve as an important source of information to ascertain the identity and to determine the quality and purity of the plant materials for future studies. These parameters also will serve as standard data for quality control studies of pharmaceutical preparations from the leaves Toddalia asiatica.

\section{ACKNOWLEDGMENT}

The author thanks Dr. P. Jayaraman, Director, Plant Anatomy Research Centre, West Thambaram, Chennai for helping in the anatomical studies.

\section{AUTHORS CONTRIBUTIONS}

All the author have contributed equally

\section{CONFLICT OF INTERESTS}

Declare none

\section{REFERENCES}

1. Yuganarasimhan SN, Assisted by Chelladurai V. Vol 2. Medicinal Plants of India; 2000.

2. Orwa JA, Jondiko IJO, Minja RJA, Bekunda M. The use of Toddalia asiatica (L) lam. (Rutaceae) in traditional medicine practise in East Africa. J Ethanopharmacol 2008;115:257-62.

3. Arun V Patil, Varsha D, Jadhav (Rathod), Poonam C Patil. Ethnomedicinal and pharmacognostical studies on leaves of Toddalia asiatica L. Pharmacia Sinica 2013;4:76-80.

4. Johansen DA, Plant Microtechnique; Mc Graw Hill Book Co: New York; 1940. p. 523.

5. Sass JE. Elements of botanical microtechnique; Mc Graw Hill Book Co: NewYork; 1940. p. 222.
6. $\mathrm{O}^{\prime}$ Brien TP, Feder N, Mc Cull ME. Polychromatic staining of plant cell walls by toluidine blue O. Protoplasma 1964;59:36473.

7. Esau K. Plant anatomy, John Wiley and Sons: New York; 1965. p. 767.

8. Harborne JB. Phytochemical methods, Chapman and Hall: International Edition, Toppan Company Ltd, Japan; 1973.

9. Mukherjee PK. Quality control of herbal drugs-an approach to the evaluation of botanicals. Business Horizons Pharmaceutical Publishers; 2002.

10. Anonymous. The ayurvedic pharmacopoeia of India. Government of India; Ministry of Health and Family Welfare: Published by The Controller of Publications, Civil Lines, New Delhi; 2001.

11. Chase CR, Pratt R. Fluorescence of powdered vegetable drugs with particular reference to the development of a system of identification. J Am Pharm Assc 1949;38:324-31.

12. Brain KR, Turner TD. Practical evaluation of phytopharmaceuticals, Wright Scientechnica: Bristol; 1975.

13. Negi JS, Singh P, Rawat B. Chemical constituents and biological importance of Swertia: a review. Curr Res Chem 2011;3:1-15.

14. Rio DA, Obdululio BG, Casfillo J, Marin FG, Ortuno A. Uses and properties of citrus flavonoids. J Agric Food Chem 1997;45:4505-15.

15. Salah N, Miler NJ, Pagange G, Tijburg L, Bolwell GP, Rice E, et al. Polyphenolic flavonoids as the scavenger of aqueous phase radicals as a chain-breaking antioxidant. Arch Biochem Broph 1995;2:339-46.

16. Rabi T, Bishayee A. Terpenoids and breast cancer chemoprevention. Breast Cancer Res Treat 2009;115:223-39.

17. Wagner KH, Elmadfa I. Biological relevance of terpenoids: an overview focusing on mono-di and tetraterpenes. Ann Nutr Metab 2003;47:95-106.

18. Sultana N, Ata A. Oleanolic acid and related derivatives as medicinally important compounds. J Enzyme Inhib Med Chem 2008;23:739-56. 